\title{
Development of water saving toilet-flushing mechanisms
}

\author{
Roubi A. Zaied ${ }^{1,2}$
}

Received: 28 August 2016 / Accepted: 28 March 2018 / Published online: 2 April 2018

(c) The Author(s) 2018

\begin{abstract}
Wasting water in toilets flushing is the largest source of water wasting through the use of old siphon boxes. It occupies the first place in domestic consumption. This study reports two trial approaches for optimizing the flushing system design. The first one employs a rotatable blade in the bottom of the bowl. This blade pushes materials in the bowl to cross the trapway thus; less toilet flushing water can be used. The second approach depends on using a rotatable trapway such that it can be tilted down to enable discharging materials in the bowl directly by its gravity. This facilitates the discharge and reduces the flushwater amount which is just used to overcome friction and to clean the passage. Both are mechanical systems actuated by an external pedal mechanism that triggers the water flushing valve system in the same time. Real experiments revealed that the first approach needs more developments to work efficiently. Experiments with restricted conditions revealed that with using the rotatable trapway system approach, less than one liter of flushwater is sufficient. The required flushwater flow rate can be obtained directly from the water supply system without the need to install siphon boxes. This study can help more to design better water saving systems.
\end{abstract}

Keywords Water saving $\cdot$ Toilet flushing $\cdot$ Pedal operated flushing system $\cdot$ Fixed trapway $\cdot$ Rotatable trapway

\section{Introduction}

According to surveyed studies, toilet flushing consumes between 25 and $35 \%$ of the total house consumption so; it occupies the first place in domestic consumption. A traditional lavatory bowl has a fixed $S$-shape outlet passage by which its exit level is elevated than the entrance level to guarantee sealing. The level difference is called seal depth. Without sealing, generated and accumulated awful gases are leaked from the sanitary system inside toilets.

Excreta consists of urine and feces that is not mixed with any flushwater. Blackwater is the mixture of urine, feces and flushwater along with anal cleansing water (if water is used for cleansing) and/or dry cleansing materials. Depending on diet, each person produces approximately 501 per year of fecal matter. Fresh feces contain about $80 \%$ water. Greywater

Roubi A. Zaied

roubi.zaied@nbu.edu.sa; rouby.nasr@bhit.bu.edu.eg

1 Department of Industrial Engineering, Faculty of Engineering, Northern Border University, Arar, Saudi Arabia

2 Department of Mechanical Engineering, Faculty of Engineering, Benha University, Benha, Egypt is the total volume of water generated from washing food, clothes and dishware, as well as from bathing, but not from toilets. Greywater accounts for approximately $65 \%$ of the wastewater produced in households with flush toilets (Tilley et al. 2014 pp. 10-11). The organic matter contributed per person per day in domestic wastewater is approximately $110 \mathrm{~g}$ of suspended solids and $90 \mathrm{~g}$ of biochemical oxygen demand (Mark et al. 2014)

Numerous proposal trials have been made to minimize water wasting in toilet flushing. Proposed solutions in surveyed studies can be generally categorized into three groups as follows:

(1) Using alternative water source such as greywater or seawater instead of fresh water

(2) Optimizing the siphon and flushing system design

(3) Using an alternative flushing way rather than using water such as vacuum.

The use of reclaimed water, in one form or another, has long been a common practice all over the world in times of drought. When and where water resources are scarce, people will have no choice but to use as little water as possible, and will naturally save the less dirty water for toilet flushing, 
floor cleansing, etc.(Tang et al. 2007 p 28). Hranova (2010) has studied on-site greywater treatment and reuse with respect to toilet flushing. Results show that the toilet flushing alternative becomes cost effective at larger population densities. Abu Rozaiza (2002), Al Mamun et al. (2014) and Suratkon et al. (2014) studied using greywater resulting from ablution facilities in toilet flushing. Recycling of greywater is a good treatment of potable water wasting problem but, it is better to make prevention (Zaied 2016). Using seawater as an alternative water source is limited to just coastal zones. $\mathrm{Ng}$ (2015) states that seawater, with minimal treatment, can be used for toilet flushing reducing the demand for freshwater in coastal cities. But seawater flushing requires a separate network of mains and, therefore, a greater capital cost and wastewater recycling has a higher ongoing treatment cost.

More engineering work has been achieved to optimize toilet flushing system design. An et al. (2012) have investigated toilet flushing performance with volume of fluid model to obtain the basic design data for the development of highefficiency toilets. Suh et al. (2009) proposed a flexible trap system that discharges feces directly from bowl hence, saves water to less than $4.5 \mathrm{~kg}$. Their flexible-trap toilet uses a straight trap and cover without the traditional trapway. Watari et al. (2013) studied the 41 toilet with new flushing technology in Japan and evaluated its drainage characteristic and the drainage-transportability. An et al. (2014) conducted a comparative analysis of the flushing and water-saving performances of a flexible-trapway toilet. The flushing performance of the toilet was quantized through the development of a measurement method to measure the accumulated flow rate and mass flow rate of the trapway with respect to time. The flexible-trapway toilet yielded stable flushing and good filth emission performance with an inflow of $4 \mathrm{~kg}$. However, the fixed-trapway toilet failed to generate a steady siphon with an inflow of $5 \mathrm{~kg}$.

This study deliberates two trial approaches for optimizing the flushing system design. Both are mechanically actuated by an external pedal mechanism. The pedal mechanism triggers, in synchronization, the water flushing valve system. It is applicable for ground base lavatory and seat lavatory systems.

\section{Modeling of flushing process}

Flushing flow of the siphon jet toilet belongs to the fluid flow problem with free surface whose shape and location would vary intricately and continually (Wang et al. 2011). Hu et al. (2014) used the finite volume method (FVM) to discrete three governing equations in space and time. The realizable turbulence model was chosen as the viscous model to treat the fluid flow with large bending curvature wall. First, a two-phase flow was simulated on the assumption that there is not sewage but water in the trap seal. Then, by simplifying the mixture of sewage and water in the trap seal as the third phase with high viscosity, a three-phase flow was simulated.

Modeling the flushing process helps studying the process variables and performing sensitivity analysis through simulation. Flushing process involves turbulence and nonlinearities especially; more than one fluid and semisolid materials are involved. In this work, three phases are considered. In the initial phase, the bowl is filled with fresh water and the mass of the water confined in the bowl $\left(M_{\mathrm{bl}}\right)$ is calculated as:

$M_{\mathrm{bl}}=\rho_{\mathrm{w}} V_{\mathrm{bl}}$

where $\rho_{\mathrm{w}}$ is the water density, $V_{\mathrm{bl}}$ is the bowl volume.

The second phase is considered during the toilet use; i.e. filling with excreta and cleansing water. During this phase, urine and cleansing water rapidly mix with water in the bowl. Soon, semi solid feces displace an equal water weight from the bowl to the sewer but, they take long time to absorb water, change their density and consequently float or sink.

The third phase starts when fresh flushwater flows down into the bowl, displaces the blackwater and replaces it. This phase is our concern to determine and optimize the flushwater flow. As blackwater is a multi-phase media contains liquids, semisolid and/or solid materials, any water added to the bowl displaces an equal water volume from the bowl to the sewer. Because of mixing with blackwater, more flushwater is required to dilute the blackwater till replacing it. Because of the difference in densities of liquids and semisolid (and/or solid) wastes, they do not move in phase during the flushing process. Relative velocities cause internal friction between the semisolids and the liquid which requires more energy for flushing. Flushwater must have sufficient mechanical energy to drive out the wastes from the bowl. There are two key factors affect the required amount of flushwater to drive out semisolids from the bowl. These factors are the density and total weight of the semisolid and/or other solid wastes. When a low specific weight-material enters the bowl from its right side in the front zone it floats (Fig. 1). Hence, to overcome the buoyancy force, more energy is required to push it down to pass the lower zone. Improperly, the flushwater usually enters the

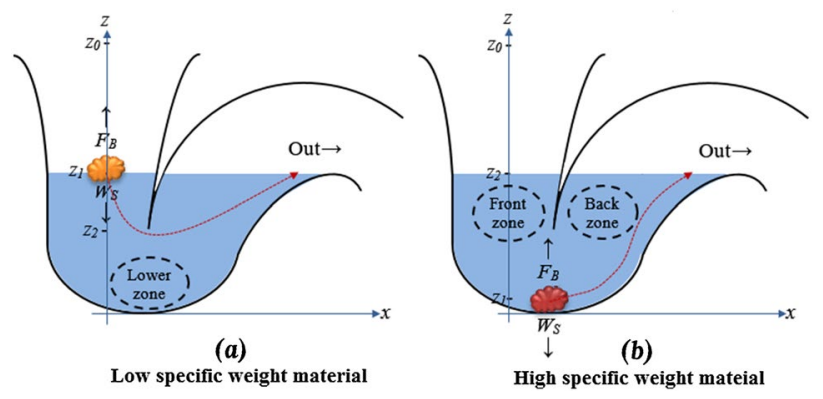

Fig. 1 A schematic diagram of wastes path in the lavatory bowl 
bowl from its boundary wall and its stream does not enter as one stream having the same cross sectional area of the bowl. Thus, light wastes resist flushing by escaping to the center. In this case, after passing sufficient amount of flushwater to generate a siphon effect, it causes the level of material in the bowl to be lowered from $Z_{1}$ to $Z_{2}$ (Fig. 1a) and so, flushing occurs. Then to secure sealing, additional flushwater is needed to fill the bowl to $Z_{1}$ level.

High specific weight-material sinks down to the lower zone and more energy is required to overcome the gravity force to push it up to pass the back zone (Fig. 1b). To estimate the flushwater amount required to overcome inertia of semisolid wastes, the flushwater is considered free falling fluid body accelerates under the influence of gravity. Sufficient amount of flushwater must be more than the blackwater in the bowl $\left(V_{\mathrm{bl}}\right)$ to replace it. The extra water amount is used to provide kinetic energy to overcome inertia and friction forces besides an additional part to clean the bowl walls. The last part is used to overcome adhesion forces between the sticky feces and the bowl walls.

When the air resistance is negligible, the acceleration of the body equals the gravitational acceleration, and acceleration in any horizontal direction is zero. The major energy loss is due to friction between the moving water and pipe wall; however, energy losses also occur from flow disturbance (Mark et al. 2014). If a flushwater of mass $m_{\mathrm{fw}}$ drops from a level of $z_{0}$ to the upper level of the front zone $\left(z_{1}\right.$ in Fig. 1a) then, by neglecting friction, its kinetic energy $\left(E_{\mathrm{k}}\right)$ can be estimated as:

$E_{\mathrm{k}}=m_{\mathrm{fw}} g\left(z_{0}-z_{1}\right)$

The energy required to move the semisolid material to the back zone is intended to be the integration of forces with respect to movements in their two directions as, it is two dimensional flow, i.e.:

Flushing Energy $=\int_{x_{1}}^{x_{2}} f_{x} \mathrm{~d} x+\int_{z_{1}}^{z_{2}} f_{z} \mathrm{~d}_{z}$

The vertical inertia force component is our concern in this work thus, it is the only force modeled. The buoyancy force acting on a body of uniform density immersed in a fluid is equal to the weight of the fluid displaced by the body and it acts upward through the centroid of the displaced volume. For floating bodies, the weight of the entire body must equal to the buoyant force, which is the weight of the fluid whose volume is equal to the volume of the submerged portion of the floating body (Çengel and Cimbala 2014). Hence, the vertical forces acting on the immersed semisolid material during its crossing from left to right (Fig. 1) are:

$$
\begin{aligned}
& F_{\mathrm{B}} \uparrow=\frac{m_{\mathrm{s}}}{\rho_{\mathrm{s}}} \rho_{\mathrm{f}} g \\
& W_{\mathrm{s}} \downarrow=m_{\mathrm{s}} g
\end{aligned}
$$

$F_{z}=m_{\mathrm{s}} g\left(1-\frac{\rho_{\mathrm{f}}}{\rho_{\mathrm{s}}}\right)$

where $F_{\mathrm{B}}$ is the buoyancy force (upward), $W_{\mathrm{s}}$ is the weight of semisolid material (downward), $M_{\mathrm{s}}$ is the mass of the submerged semisolid material, $\rho_{\mathrm{f},} \rho_{\mathrm{s}}$ is the densities of the fluid in the bowl and the semisolid material, respectively, $g$ is the gravitational acceleration, $F_{\mathrm{Z}}$ is the net vertical force acting on the semisolid material.

Based on physics principles published by Halliday: A totally submerged object that is less dense than the fluid in which it is submerged experiences a net upward force and a totally submerged object that is denser than the fluid sinks (Halliday 1999 p. 467). So, net $F_{\mathrm{Z}}$ is upward for $\frac{\rho_{\mathrm{f}}}{\rho_{\mathrm{s}}}>1$ and downward for $\left.\frac{\rho_{\mathrm{f}}}{\rho_{\mathrm{s}}}<1\right)$. Now, the net vertical force is to be integrated with respect to the vertical travel to estimate the work required against the buoyancy force to move the semisolid material from $z_{1}$ to $z_{2}$. The energy required to overcome the semisolid inertia $\left(E_{i}\right)$ is estimated as follows:

$E_{i}=\int_{z_{1}}^{z_{2}} f_{z} \mathrm{~d} z=\int_{z_{1}}^{z_{2}} m_{\mathrm{s}} g\left(1-\frac{\rho_{\mathrm{f}}}{\rho_{\mathrm{s}}}\right) \mathrm{d} z$

$E_{i}=m_{s} g\left(1-\frac{\rho_{f}}{\rho_{s}}\right)\left(z_{2}-z_{1}\right)$

These equations are applicable for both cases (Fig. 1a, b) with noticing the positions of $z_{1}$ to $z_{2}$ for each case.

By equating the energies in Eqs. 2 and 8, the relative mass of the flushwater $\left(m_{\mathrm{fw}}\right)$ needed to overcome inertia of semisolid wastes $\left(m_{\mathrm{s}}\right)$ can be approximated as:

$\frac{m_{\mathrm{fw}}}{m_{\mathrm{s}}}=\left(1-\frac{\rho_{\mathrm{f}}}{\rho_{\mathrm{s}}}\right)\left(z_{2}-z_{1}\right) /\left(z_{0}-z_{1}\right)$

Some typical data are used to realize the effect of relative elevation of flushwater source $\left(Z_{0}-Z_{1}\right)$ and relative densities of blackwater and semisolid $\left(\rho_{f} / \rho_{s}\right)$ on relative mass of flushwater required $\left(m_{\mathrm{fw}} / m_{\mathrm{s}}\right)$ as shown in Fig. 2. Data presented in this figure are based on setting $\left(Z_{2}-Z_{1}\right)=10 \mathrm{~cm}$ for $\rho_{\mathrm{f}} / \rho_{\mathrm{s}}>1$ and $\left(Z_{2}-Z_{1}\right)=20 \mathrm{~cm}$ for $\rho_{\mathrm{f}} / \rho_{\mathrm{S}}<1$ as depicted in Fig. 1. It can be concluded that the relative mass of flushwater required highly depends on the potential energy of the falling flushwater and the relative densities of blackwater and semisolid. For instance, based on the supposed values of $Z_{1}$ and $Z_{2}$, if the flushwater tank or source is elevated only $10 \mathrm{~cm}$ above the level of water in the bowl, the relative mass of flushwater is equivalent to $\rho_{\mathrm{f}} / \rho_{\mathrm{s}}$ for light semisolids whereas but, it is multiplied 10 times for dense semisolids when $\rho_{\mathrm{f}} / \rho_{\mathrm{s}}$ changes from 1.5 to 2 . This means that dense semisolids needs more flushing energy because their upward travel against gravity in the bowl is longer. 
Fig. 2 Effect of flushwater source elevation and relative densities on relative mass of flushwater required

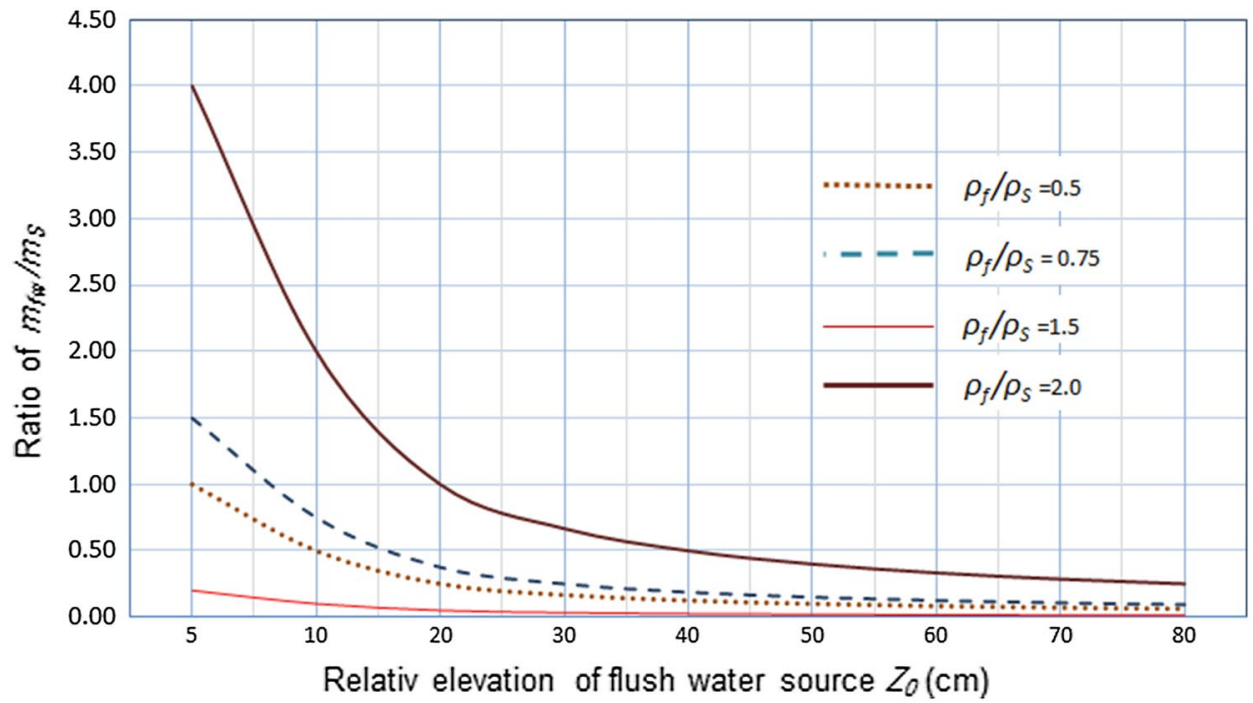

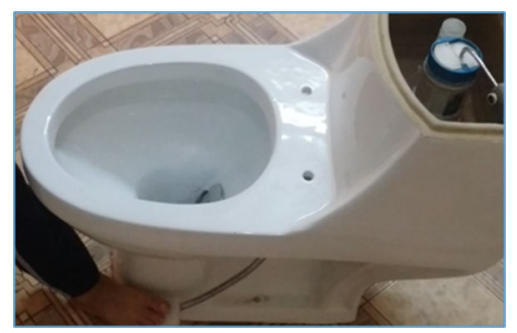

Fig. 3 A schematic diagram of a proposed bowl-rotatable blade system

\section{Methodology}

\section{First trial}

The first trial to decrease flushwater wasting depends on using a mechanical system to push out waste materials from the bowl. A rotatable blade is installed in the bottom of the bowl that pushes out materials at onset of the flushing action thus; less toilet flushwater can be used. This proposed mechanism is designed and implemented on a common lavatory seat. Installation of the mechanism requires only some holes in the ceramic seat. The key idea of the system is illustrated in Fig. 3 and the actual application is pictured in Fig. 4.

The system is composed of an external pedal (plastic pad and steel lever) drives a mechanism that pulls the string to turn the blade counterclockwise and the return spring retain the blade to its initial position when the pedal is released. The string is a threaded stainless steel wire and the blade and its bracket are made from aluminum to ease their manufacturing. For real application, stainless steel is recommended for all parts including the screws and the
Fig. 4 Application of bowl-rotatable blade on a ceramic seat

return spring. The pedal actuates the flushing system in the same time when it is depressed through a lever mechanism consisting of two steel levers and a plastic pipe. There is a time shift such that the pedal movement releases the flushwater when the blade rotation angle exceeds $180^{\circ}$. Two sorts of blades are tried (both are made from aluminum); a solid one and another perforated one as shown if Figs. 5 and 6, respectively. The solid blade can sweep urine in addition to feces where perforated blade is intended to flush feces only to decrease the required actuation force by decreasing the total exposed area.

Dry run experiments are used to check the mechanical system functionality and other wet runs are done to investigate the real functionality and flushwater saving.

\section{Second trial}

In traditional lavatory systems, flushwater drives blackwater till it passes the back zone and enters the exit pipe. In the study of An et al. (2014), weight of some water from the flushing box is used in tilting down a $U$-shape trapway. It has a spring located in large corrugated flexible tube that contracts prior to flushing due to the elastic strain energy of the spring to maintain a certain slope. A certain amount of 


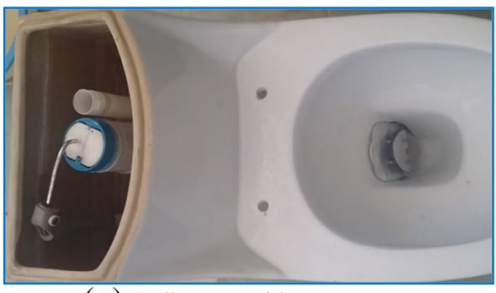

(a) Ordinary position

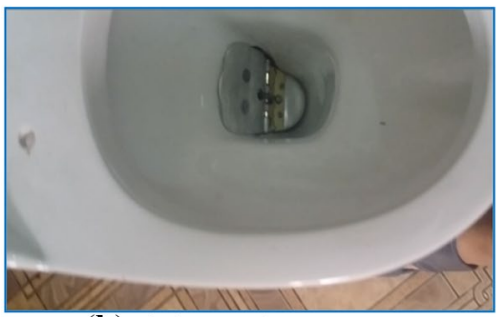

(b) Blade rotated $120^{\circ}$

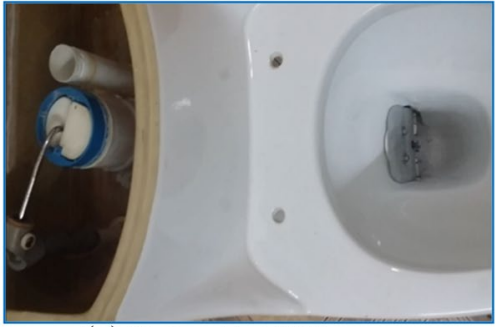

(c) Blade rotated $225^{\circ}$

Fig. 5 Steps of moving down solid rotatable blade

water flows into the corrugated flexible tube once flushing begins. Once the mass of the inflowing water becomes larger than the elastic energy of the spring, the corrugated flexible tube relaxes to the bottom, making the slope of the trapway horizontal and facilitating the discharge of waste.

In our second approach, this idea is developed and simplified. The trapway is rotatable by which it can be tilted down to enable discharging blackwater from the bowl directly by gravity. Hence, flushwater is just used to overcome friction and to clean the passage. The method is illustrated in Fig. 7 and the experimental setup for the proposed system is pictured in Fig. 8. A mechanism is installed inside the seat between the bowl and the exit pipe fitting. Angles $\alpha_{\mathrm{O}}, \beta_{\mathrm{O}}$ and $\gamma_{O}$ are rotation angles, from vertical axes in the ordinary position, of the Pedal, trapway pipe and water valve handle, respectively, where $\alpha_{\mathrm{f}}, \beta_{\mathrm{f}}$ and $\gamma_{\mathrm{f}}$ are there angles in the extreme position.

The trapway pipe is installed between two flexible tubes and rotates about fixed hinge. The pedal mechanism, when depressed, pushes the trapway pipe down; the right side flexible tube expands and the left side flexible tube contracts. The gate valve handle is linked to the pedal; the vale is normally closed under the weight of water column over it in ordinary position (Fig. 7a). In this position, when blackwater is filling the bowl and its level does not exceed the bottom

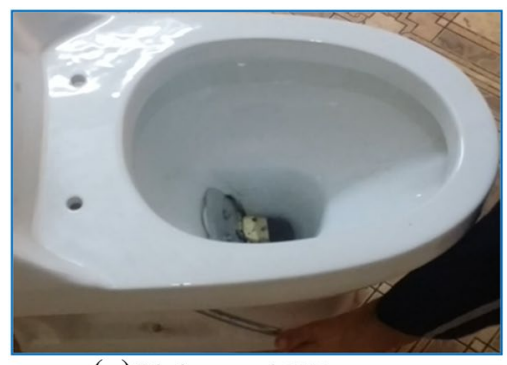

(a) Blade rotated $120^{\circ}$

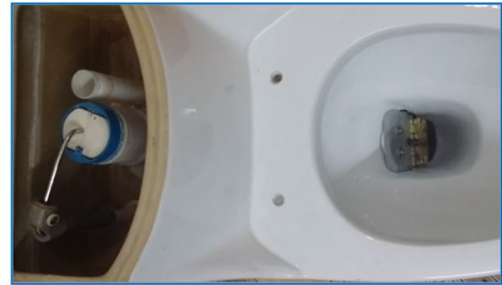

(b) Blade rotated $180^{\circ}$

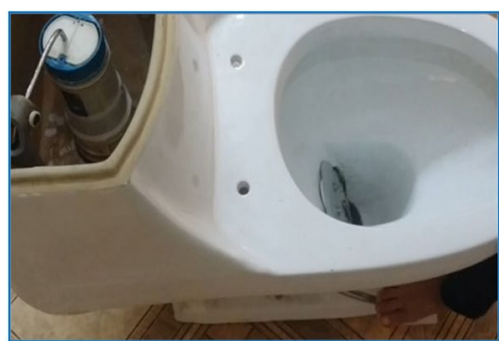

(c) Blade rotated $210^{\circ}$

Fig. 6 Steps of moving down perforated rotatable blade

level of the trapway pipe; any more water passes directly to the exit pipe. The flushing gate valve starts to open and release water after certain rotation angle of the pedal. The tension spring between the lavatory base and the trapway pipe retains it to the ordinary position when the pedal is released after depressing it. In extreme discharge position (Fig. 7a), the trapway pipe is tilted down and the flushing vale is at its maximum opening position, thus blackwater moves to left side and running flushwater helps to overcome friction and cleans bowl and the whole trapway. The timing diagram of the system is illustrated in Fig. 9 that depicts the synchronization between the pedal movement, trapway rotation, flushwater valve and flushwater flow. Table 1 summarizes the specifications of the experimental apparatus.

To analyze the system performance, dices of internal melon shell is found suitable to simulate feces regarding its density. Its specific weight is 0.9 ( $150 \mathrm{~g}$ has a volume of $167 \mathrm{~cm}^{3}$ ) and each dice is about $3 \mathrm{~g}$. Figure 10 shows the melon dices used in the experiment inside the measuring cup and inside the bowl while running the experiments.

Two different quantities of dices are used in the experiments; 99 and $150 \mathrm{~g}$. In each experiment run, the siphon box is filled with definite amount of flushwater e.g. $500 \mathrm{ml}$ or $1000 \mathrm{ml}$ to be discharged as one time batch instead of

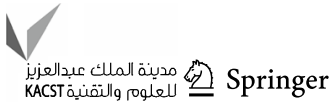


Flushing water $\downarrow$

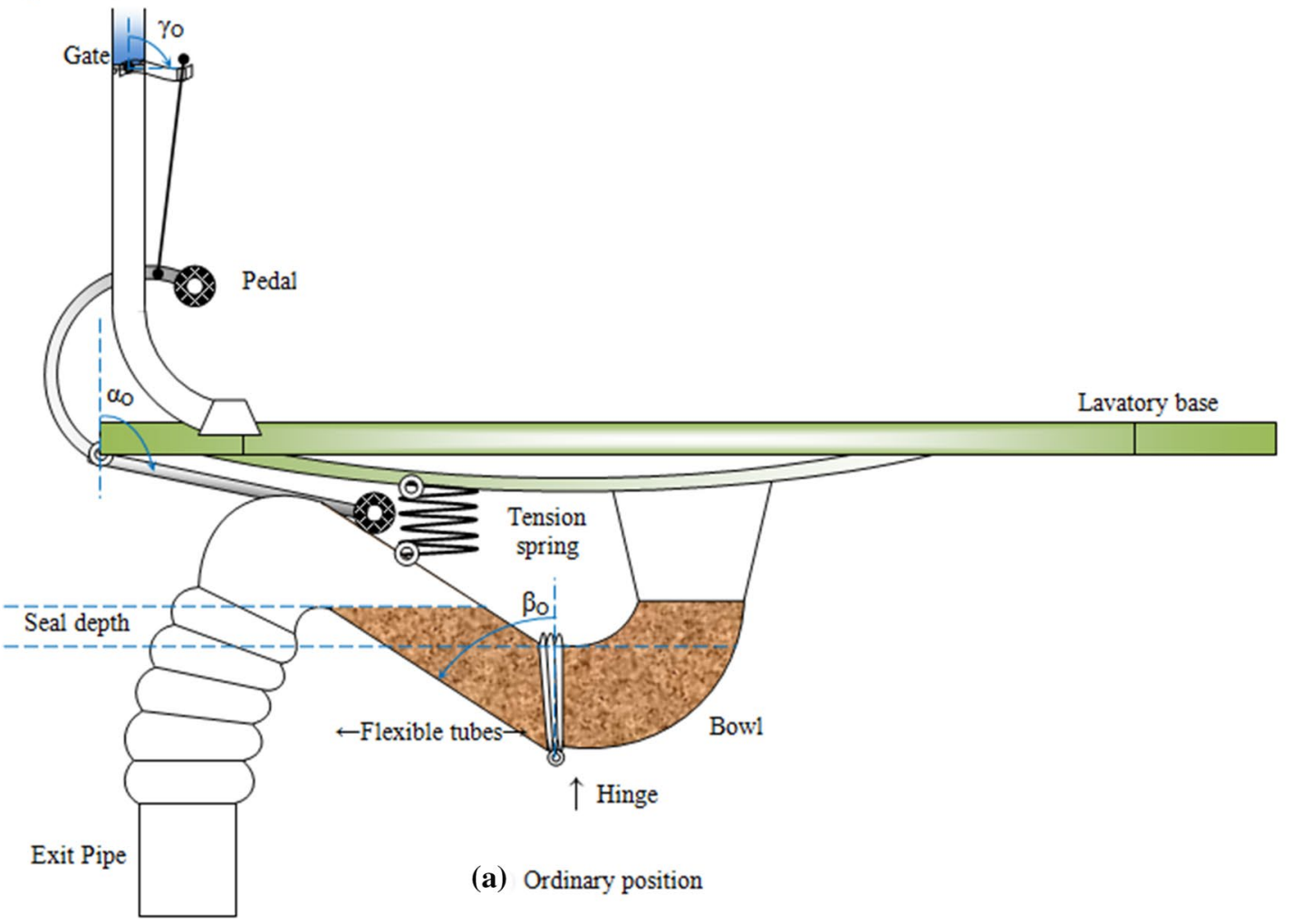

Flushing water $\downarrow$

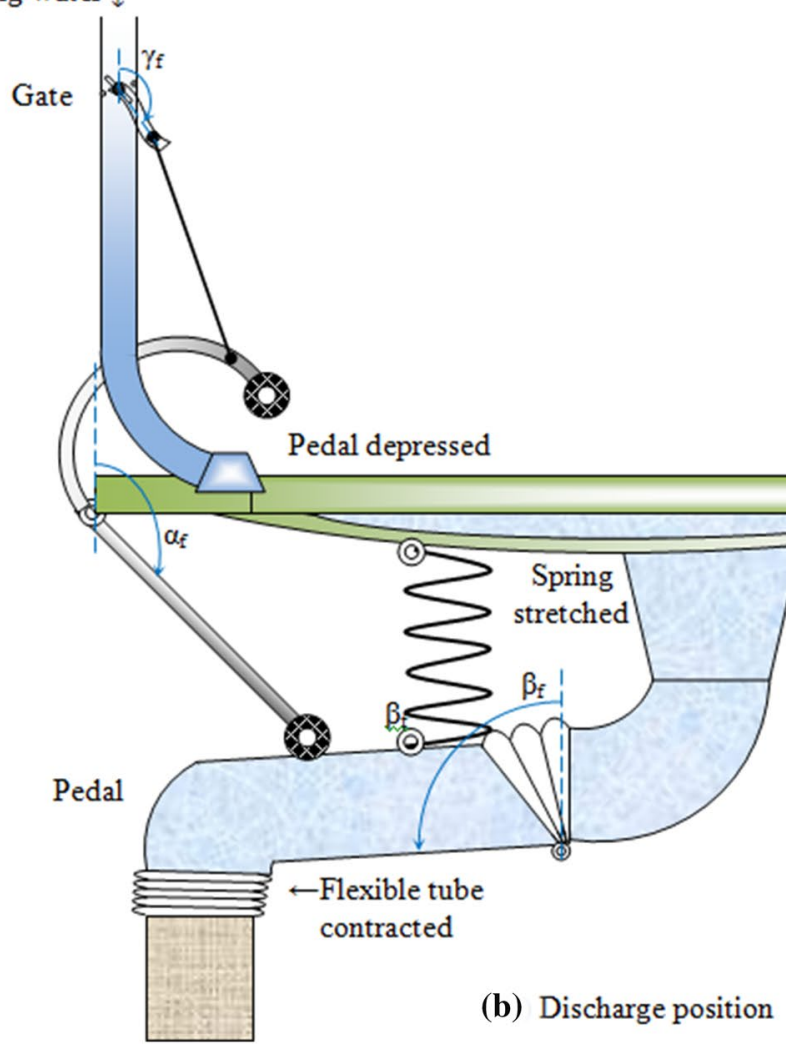

Fig. 7 A schematic diagram of a proposed rotatable trapway system 


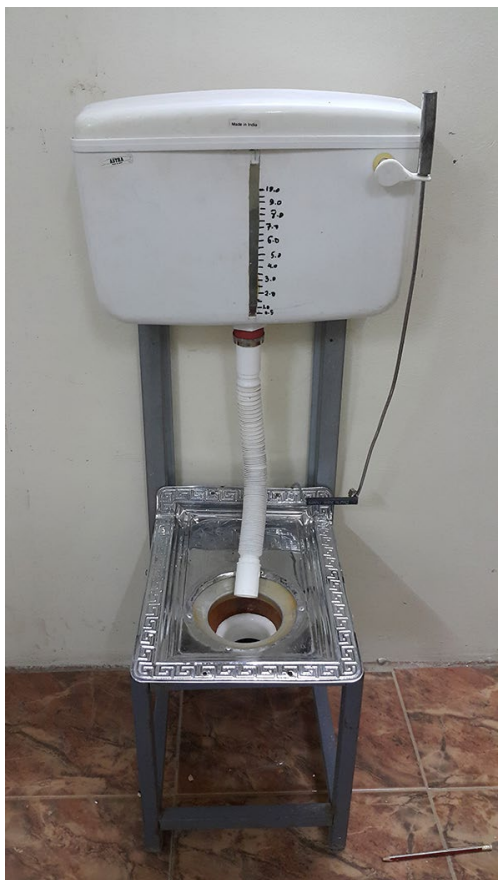

Fig. 8 The experimental setup for the proposed rotatable trapway system

controlling the time of flow. In each run, the bowl is filled with fresh water and then dices are added. For fixed trapway experiments, flushing valve only is opened to discharge the siphon box water to the bowl without depressing the pedal and, for the rotatable trapway the pedal is depressed to rotate the trapway pipe and to open the flushing gate vale simultaneously. Four experiment groups are implemented for different trapway type and dices weight mutually at suitable amounts of water filled in the siphon box. Each experiment is repeated 5 times and the average values are considered. Table 2 summarizes the obtained results of different 12 experiments.

\section{Experimental results and discussion}

When the proposed bowl-rotatable blade system was testes by dry run it functioned well but, when the bowl is filled with water and melon dices it functioned badly. The melon dices tend to escape from the blade side to wide gap and some dices are stuffed between the blade and the bowl wall. In sometimes, the blade was stuck in its vertical position and, therefore, the design needs major revising. No more trials are made to redesign bowl-rotatable blade system. The second approach of rotatable trapway seems more promising.

Analyzing the data in Table 2 confirms that the rotatable trapway has superior performance in water saving. To be noticed that according to the mentioned procedure of the experiments, the amounts of flushwater used do not express truthfully the real amount of water required to replace the blackwater. The figures in this table give only a comparative aspect of flushing in the two cases of fixed trapway and the rotatable one. For example, the last figure in the Table (98\%) means that 21 of flushwater when being discharged from the siphon box at flowrate of $10.7 \mathrm{l} / \mathrm{min}$ could displace out $98 \%$ of the dices to the exit pipe. But in real application more water is required to replace all the blackwater in the bowl. Also $0.5 \mathrm{l}$ of flushwater at flowrate of $3.2 \mathrm{l} / \mathrm{min}$ could displace out $100 \%$ of the dices to the exit pipe of a tilted trapway. Really, additional amount of at least $365 \mathrm{ml}$ is
Fig. 9 Timing diagram of the proposed pedal actuated-rotatable trap way system

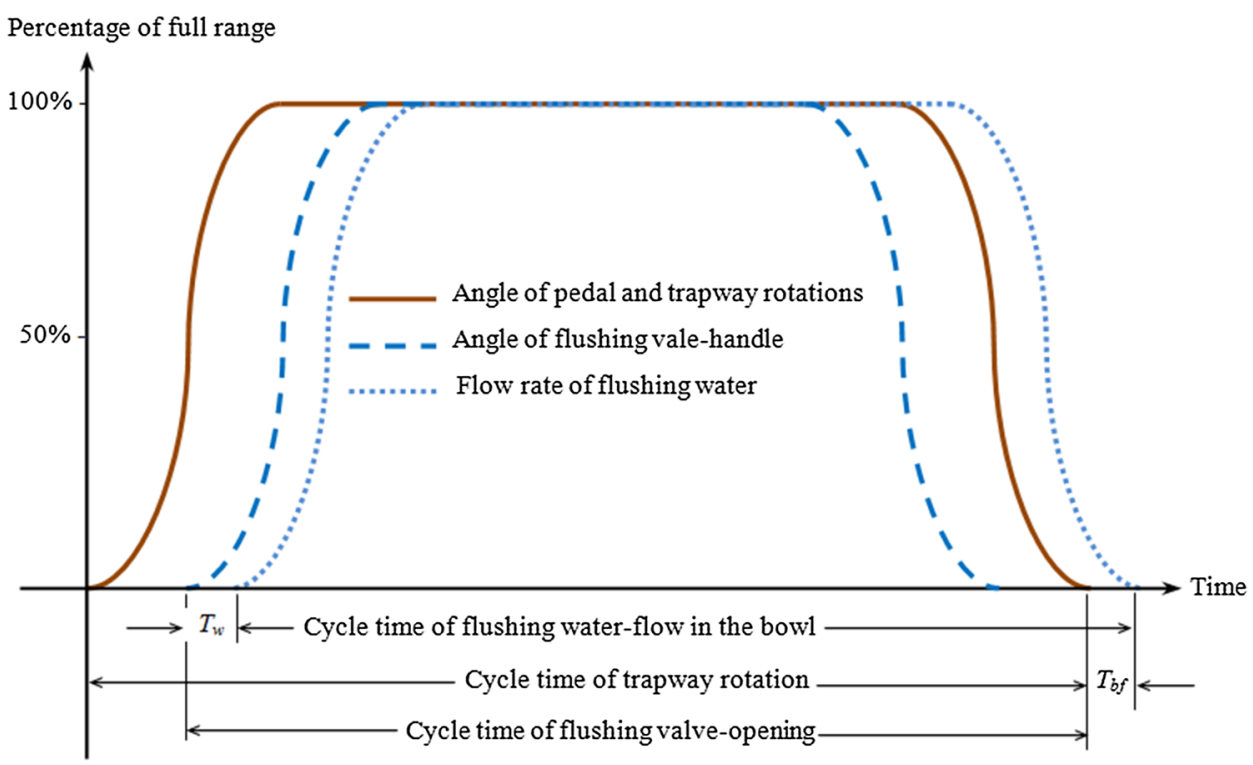

$T_{w}$ : Time of flushing water to flow from the valve to the bowl surface $T_{b f}$ : Time of residual flushing water to fill the bowl retained its ordinary position 
Table 1 Specifications of the experimental apparatus

\begin{tabular}{|c|c|c|c|}
\hline Parameter & Value & Parameter & Value \\
\hline Capacity of the bowl & $365 \mathrm{~mL}$ & Capacity of the siphon box & $10 \mathrm{~L}$ \\
\hline $\begin{array}{l}\text { Minimum pressure Head (from the Lavatory base To the } \\
\text { siphon box) }\end{array}$ & $50 \mathrm{~cm}$ & Maximum downward vertical travel of the pedal & $5 \mathrm{~cm}$ \\
\hline Range of pedal rotation angle $\left(\alpha_{\mathrm{O}}-\alpha_{\mathrm{f}}\right)$ & $120^{\circ}-150^{\circ}$ & Nominal trapway diameter ${ }^{\mathrm{b}}$ & $8 \mathrm{~cm}$ \\
\hline Range of trapway pipe rotation angle $\left(\beta_{\mathrm{O}}-\beta_{\mathrm{f}}\right)$ & $50^{\circ}-120^{\circ}$ & Seal depth ${ }^{\mathrm{b}}$ & $2 \mathrm{~cm}$ \\
\hline Range of water valve-handle rotation angle $\left(\gamma_{\mathrm{O}}-\gamma_{\mathrm{f}}\right)$ & $90^{\circ}-120^{\circ}$ & Material of flexible tubes and pedal rollers & Rubber \\
\hline
\end{tabular}

${ }^{a}$ The selection of this parameters is based on: "Although higher water level in the water tank shows better performance in flushing, lower water level is preferred to save water. Too low water level may cause dirt to clog the trapway due to relatively weak siphon" (An et al. 2012)

${ }^{\mathrm{b}}$ The selection of these parameters is based on: "The optimal depth of the water seal head is approximately $2 \mathrm{~cm}$ to minimize the water required to flush the excreta. The trap should be approximately $7 \mathrm{~cm}$ in diameter" (Tilley $2014 \mathrm{p} \mathrm{50)}$

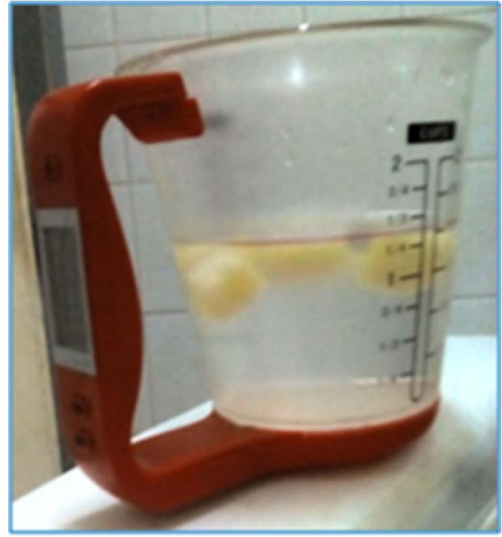

(a) Dices in the measuring cup

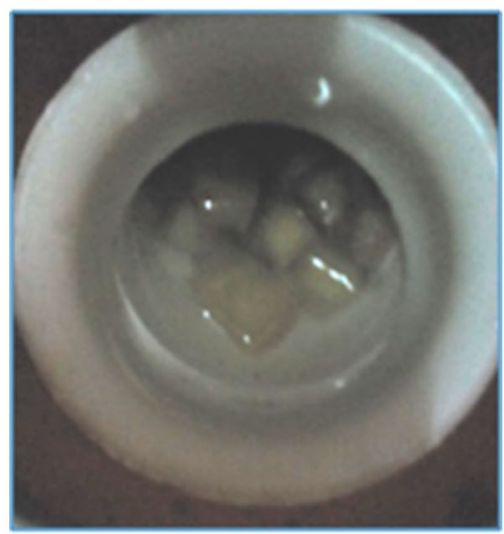

(b) Dices in the bowl

Fig. 10 Melon dices used in the experiment

required to refill the bowl after retaining the trapway pipe to its ordinary position. The required flushwater flowrate can be obtained directly from the fresh water supply system without the need to install siphon boxes. The final result of this analysis is that less than one liter of flushwater is sufficient with using the rotatable trapway system approach.
Table 2 Results obtained of experiments on the pedal actuated-rotatable trap way system

\begin{tabular}{|c|c|c|c|c|c|}
\hline \multirow[t]{2}{*}{$\begin{array}{l}\text { Flushwater } \\
\text { amount (1) }\end{array}$} & \multirow[t]{2}{*}{$\begin{array}{l}\text { Flushwater } \\
\text { flowrate }(1 / \mathrm{min})\end{array}$} & \multicolumn{2}{|c|}{$\begin{array}{l}\text { Fixed trapway } \\
\text { Average percent- } \\
\text { ages of melon } \\
\text { dices flushed of }\end{array}$} & \multicolumn{2}{|c|}{$\begin{array}{l}\text { Rotatable } \\
\text { trapway } \\
\text { Average } \\
\text { percentages of } \\
\text { melon dices } \\
\text { flushed of }\end{array}$} \\
\hline & & $99 \mathrm{~g}$ & $150 \mathrm{~g}$ & $99 \mathrm{~g}$ & $150 \mathrm{~g}$ \\
\hline 0.250 & 1.2 & - & - & $45.7 \%$ & - \\
\hline 0.300 & 1.9 & - & - & - & $25.5 \%$ \\
\hline 0.350 & 2.1 & - & - & $72.7 \%$ & - \\
\hline 0.400 & 2.7 & - & - & - & $71.9 \%$ \\
\hline 0.500 & 3.2 & $19.7 \%$ & - & $100 \%$ & $100 \%$ \\
\hline 1.000 & 5.5 & $78 \%$ & $33.6 \%$ & - & - \\
\hline 1.500 & 7.5 & $82.7 \%$ & $40.6 \%$ & - & - \\
\hline 2.000 & 10.7 & - & $98 \%$ & - & - \\
\hline
\end{tabular}

Actually, blackwater sewer pipes are more prone to clogging than greywater sewer pipes because of higher viscosity of blackwater. In typical domestic sanitary systems, large pipes of 4-5 inches dimeter are used for blackwater sewer while thinner pipes of 1.5-3 inches dimeter are used for greywater sewer. In multistory buildings, main sewer pipes are installed vertically behind toilets and kitchens as separate columns for blackwater and separate columns for greywater and mixing them occurs at end points before sending them to the main municipal sewer network. This separation secure hindering of blackwater reflection to greywater drains in case of clogging of their passages. Using small amount of flushwater may cause high viscosity of the black water in blackwater pipes causing clogging. To avoid this, pipes of blackwater must be joined with greywater pipes at the closest point in the ground level. Mixing greywater with blackwater before sending them to the main sanitation duct can help in prevention of system clogging. 
Table 3 Relative costs of traditional, rotatable blade mechanism and rotatable trapway systems

\begin{tabular}{llll}
\hline $\begin{array}{l}\text { Cost category } \\
\text { Flushing system }\end{array}$ & $\begin{array}{l}\text { Relative } \\
\text { installation } \\
\text { cost }\end{array}$ & $\begin{array}{l}\text { Relative } \\
\text { maintenance } \\
\text { cost }\end{array}$ & $\begin{array}{l}\text { Relative } \\
\text { flushwater } \\
\text { cost }\end{array}$ \\
\hline $\begin{array}{l}\text { Traditional system } \\
\text { Rotatable blade system }\end{array}$ & Low & Low & Very high \\
Rotatable trapway system & High & High & Low \\
\hline
\end{tabular}

\section{Cost analysis and economic feasibility}

The costs of first proposed system (the rotatable blade mechanism) include cost of materials and that of changing the typical manufacturing routine. In the experimental work of this study, the cost of the mechanism parts is about $20 \%$ of the ceramic base price. Improving the mechanism design may include additional costs, thus its feasibility depends on the final applicable design. The second approach is considered seems more promising and feasible. Manufacturing, installation and maintenance of the rotatable trapway system will rise its cost but it reduces the cost of flushwater considerably as well. As to the author experience, the cost increment can be $40-80 \%$. As the mechanical pedal system is prone to malfunctions and its appearance is not desired in hotels and some facilities, the actuation system can be automated. A small electric motor, a cam mechanism, a solenoid valve and a minor control circuit can be used instead with additional cost of $20-50 \%$. A system is considered feasible if the cost of water saved by it surpasses its installation, running and maintenance costs during its useful life. Relative cost comparison is presented in Table 3 for costs of traditional, rotatable blade mechanism and rotatable trapway systems.

A system total annual cost can be modeled as follows:

$T_{\mathrm{c}}=W_{\mathrm{c}}+D_{\mathrm{c}}+M_{\mathrm{c}}$

where $\mathrm{T}_{\mathbf{c}}$ is the Annual total cost, $\mathrm{W}_{\mathbf{c}}$ is the Annual flushwater cost, $D_{\mathrm{c}}$ is the Annual deterioration cost (Installation cost divided by its useful life in years), $M_{c}$ is the Annual maintenance cost.

Change in Annual cost when replacing a traditional toilet and its flushing system:

$\Delta T_{\mathrm{C}}=T_{\mathrm{CN}}-T_{\mathrm{CO}}$

where $\boldsymbol{T}_{\mathrm{cN}}$ and $\boldsymbol{T}_{\mathrm{cO}}$ are the total costs for the new and old system, respectively.

For economic feasibility decision to be made, definite figures are required for real costs of manufacturing, installation and maintenance.

\section{Conclusions}

Through the literature survey and experimental work, it was found that:

- Plentiful studies, trials and proposals have been made to minimize water wasting in toilet flushing and the proposed solutions included using greywater or seawater water as alternative source instead of fresh water, optimizing the siphon and flushing system design and using an alternative rather than water such as vacuum.

- Flushwater must have sufficient mechanical energy to drive out waste materials from the bowl.

- There are two key factors affect the required amount of flushwater required: the density and total weight of the feces or semisolids.

- This study deliberates two mechanically actuated trial system approaches for optimizing the flushing system design applicable for ground base lavatory and seat lavatory systems.

- The first trial depends on using a rotatable blade in the bottom of the bowl as a mechanical mean to push solid or semisolid materials from the bowl but, real testing of one design revealed poor performance.

- The second approach depends on making the trapway rotatable by which it can be tilted down to enable discharging blackwater from the bowl directly by its gravity. Hence, water is just used to overcome friction and to clean the passage

- Experiments with restricted conditions revealed that less than one liter of flushwater is sufficient with using the rotatable trapway system approach. The required water flowrate can be obtained directly from the water supply system without the need to install siphon boxes.

\section{Recommendations and future work}

Researchers are encouraged to enhance the rotatable blade system design as its application will be easier on the existing lavatories without major change in the manufacturing and installation systems. The rotatable trapway seems promising in super saving of water but, more research work is required to improve its reliability and manufacturability.

Acknowledgement Praise is due to Allah for his refinement. Then, thanks to the Northern Border University for sponsoring the research; especially the Deanship of Scientific Research. Thanks to my family and my colleagues who supported me to complete it. I ask Allah that the results of this research promise and benefit everyone.

Open Access This article is distributed under the terms of the Creative Commons Attribution 4.0 International License (http://creativeco

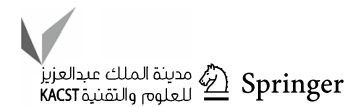


mmons.org/licenses/by/4.0/), which permits unrestricted use, distribution, and reproduction in any medium, provided you give appropriate credit to the original author(s) and the source, provide a link to the Creative Commons license, and indicate if changes were made.

\section{References}

Abu Rozaiza OS (2002) Ablution water: prospects for reuse in flushing of toilets at mosques, schools, and offices in Saudi Arabia. J King Abdul Aziz Univ-Eng Sci 14(2):3-28

Al Mamun A, Muyibi SA, Abdul Razak NA (2014) Treatment of used ablution water from IIUM masjid for reuse. Adv Environ Biol 8(3):558-564

An IY, Lee YL, Jo WS, Kim JH (2012) A study on development of high efficiency toilets with VOF numerical analysis. J Korean Soc Manuf Technol Eng 21(6):946-953. https://doi.org/10.7735/ ksmte.2012.21.6.946

An IY, Lee YL, Kim J-H (2014) A study of the characteristics of a super water-saving toilet with flexible trapway by measuring accumulated flow rate. J Mech Sci Technol 28(8):3067-3074. https:// doi.org/10.1007/s12206-014-0714-1

Çengel YA, John M, Cimbala JM (2010) Fluid mechanics fundamentals and applications, 2nd edn. McGraw-Hill, New York. ISBN 978-007-128421-9

Halliday (1999) Fundamentals of physics, 8th edn. Wiley, New York, p 467

Hranova R (2010) Application of a system approach and optimisation of different alternatives in the practice of decentralised wastewater reuse. Civil Eng Environ Syst 27(4):281-294

Hu JG, Sun YS, Zhang ZR (2014) Numerical simulation and experimental validation of three-dimensional unsteady multi-phase flow in flushing process of toilets. Appl Mech Mater 444-445:304-311
Mark J, Hammer Sr, Mark J, Hammer Jr (2014) Water and wastewater technology, 7th edn. Pearson, London. ISBN 978-1-292-02014-1

$\mathrm{Ng}$ TL (2015) Cost comparison of seawater for toilet flushing and wastewater recycling. Water Policy 17(1):83-97

Suh KW, Won YJ, Lee YH (2009) A study on the water saving device using a variable position straight trap in water closet system. The Society of Air-Conditioning and Refrigerating Engineers of Korea, pp. 465-470

Suratkon A, Chee MC, Ab Rahman TST (2014) SmartWUDHU: recycling ablution water for sustainable living in Malaysia. J Sustain Dev 7(6):150-157. https://doi.org/10.5539/jsd.v7n6p150

Tang SL, Yue DPT, Ku DCC (2007) Engineering and costs of dual water supply systems. IWA Publishing, London. ISBN 1843391325 and 9781843391326

Tilley E, Ulrich L, Lüthi C, Reymond P, Zurbrügg C (2014) Compendium of sanitation systems and technologies, 2nd edn. Swiss Federal Institute of Aquatic Science and Technology (Eawag), Duebendorf

Wang Y, Xiu G, Tan H (2011) CAD and CAE analysis for siphon jet toilet. In: International Conference on Optics in Precision Engineering and Nanotechnology 2011, ScienceDirect. Physics Procedia 19 (2011) 472-476, https://doi.org/10.1016/j.phpro .2011 .06 .194

Watari K, Otsuka M, Kitamura S (2013) A study of 4 liter toilet with new flushing technology. In: CIBW062 Symposium, pp. 105-116

Zaied RA (2016) Water use and time analysis in ablution from taps. Appl Water Sci. https://doi.org/10.1007/s13201-016-0407-2

Publisher's Note Springer Nature remains neutral with regard tojurisdictional claims in published maps and institutional affiliations. 